\title{
Ocular findings in Saudi Arabian patients with sickle cell disease
}

\author{
Selwa Al-Hazzaa, Alan C Bird, Andreas Kulozik, Beryl E Serjeant, Graham R Serjeant, \\ Peter Thomas, Andrew Padmos
}

\begin{abstract}
Aim-This study was set up to determine whether or not retinal changes occur in sickle cell disease in Saudi Arabian subjects with either the Benin, which exists in the south western part of the kingdom, or Asian haplotypes in the east, and to compare the findings with those in sickle cell disease in Jamaica.
\end{abstract}

Methods-Retinal examination and fluorescein angiography were performed in 61 patients with SS disease (40 eastern, 20 south western, 1 central region) and 10 with sickle cell $\beta^{0}$ thalassaemia.

Results-Peripheral retinal vascular changes were common, and a qualitatively abnormal vascular border believed to imply risk of proliferative sickle retinopathy (PSR) was significantly more common in south western SS patients and PSR was shown in one of these. There were no differences in visual acuity, the presence of peripheral retinal patches, or the circumferential or posterior extent of peripheral retinal vessel closure between SS disease and sickle cell $\beta^{0}$ thalassaemia or between SS disease in the two regions. Compared with the Jamaican Cohort Study, $>180^{\circ}$ of the peripheral retinal vasculature was seen significantly less frequent, suggesting factors inhibiting vascular remodelling in Saudi patients in early life.

Conclusion-Sickle cell disease in Saudi Arabia affects the retina and represents a potential threat to vision. Changes occur whatever the haplotype, and is similar to that observed in Jamaica.

(Br f Ophthalmol 1995; 79: 457-461)

Sickle cell disease in Saudi Arabia presents interesting and instructive differences from that observed in populations of African origin. The mutation in the south west of the kingdom is of the Benin haplotype, is probably imported from Africa, and has similar levels of fetal haemoglobin ( $\mathrm{HbF}$ ) to those observed in African patients with the same haplotype. ${ }^{1}$ In the eastern province, there has probably been an independent mutation of the sickle cell gene, the so-called Asian haplotype, ${ }^{2}$ which is associated with higher levels of $\mathrm{HbF}^{3}$ In both areas, the disease coincides with high frequencies of $\alpha$ thalassaemia. There are differences in haematological and clinical features of SS disease between the two regions of Saudi Arabia ${ }^{1}$ which in the absence of obvious environmental differences, are presumed to reflect these genetic differences. There are no reports of retinal involvement in sickle cell disease in Saudi Arabia. Observations from general clinical features suggest that patients from the south west might have sickle cell retinopathy similar to that observed in patients of African origin, whereas those in the east with both high $\mathrm{HbF}$ levels and frequent $\alpha$ thalassaemia should be protected from vaso-occlusion and consequently show little retinal damage. The present study had two objectives: firstly, to learn whether sickle cell eye disease occurs in Saudi Arabia; and, secondly, to use the opportunity of the genetic and haematological diversity of Saudi patients with sickle cell disease, to learn more about the risk factors for retinal involvement.

\section{Patients and methods}

\section{PATIENTS}

The patients attended the sickle cell clinic operated by the Department of Oncology at King Faisal Specialist Hospital, Riyadh, Saudi Arabia. This clinic serves patients resident in the Riyadh area but also conducts biannual assessments of patients from both the eastern and south western provinces where sickle cell disease is relatively common. The study was confined to patients showing only haemoglobins F, S, and A2 on haemoglobin electrophoresis - that is, homozygous sickle cell (SS) disease or sickle cell $\beta^{0}$ thalassaemia $\left(S \beta^{0}\right.$ thalassaemia), aged 17 years and above who had fluorescein angiography and angioscopy allowing description of the peripheral retinal vascular border. A total of 88 patients had been previously characterised and all were given appointments during a 5 day period in April 1993. Seventy four (84\%) attended but three SS patients were excluded on the basis of penetrating ocular trauma (one), high myopia (one), and no veins for fluorescein angiography (one). The study group comprised 71 patients, 61 with $S S$ disease (33 male) and 10 with $S \beta^{0}$ thalassaemia (five male). The patients were further divided according to geographical origin, 44 (40 SS, four $S \beta^{0}$ thalassaemia) originating in the eastern province, 25 (20 SS, five $S \beta^{0}$ thalassaemia) from the south west, and two (one SS, one $S \beta^{0}$ thalassaemia) from the central region. Data from these last two patients were used in the genotype comparison but the SS subject from the central region was excluded from the analyses comparing features of the eastern and south western regions. 


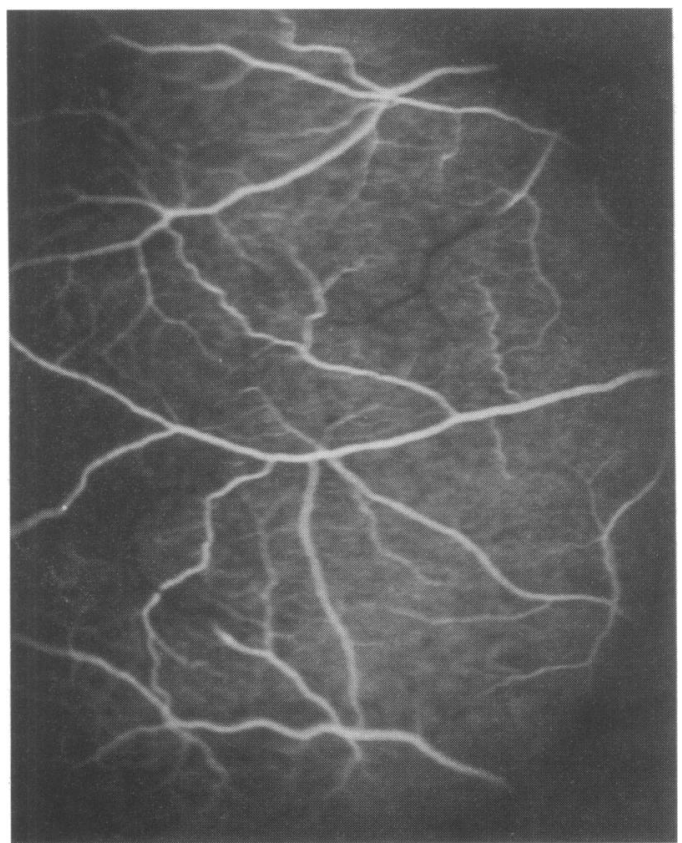

Figure 1 Fluorescein angiogram of a 17-year-old man with $S S$ disease from the eastern region showing occlusion of an artery. There is a hypofluorescent column beyond the vessels implying a recent event.

The age of patients with $S \beta^{0}$ thalassaemia (mean 24.5 (SD 4.9) years) did not differ from that in SS disease (mean 27.7 (SD 6.4); $t$ test, $\mathrm{p}=0 \cdot 13$ ) and that of eastern SS patients (mean $28 \cdot 4$, range 17-44 years) did not differ from those in the south west $(26 \cdot 7$, range $17-40$ years; $t$ test, $\mathrm{p}=0.32$ ). The sex of SS patients did not differ between regions, males accounting for 23/40 eastern and 9/20 western patients respectively ( $\chi^{2}$ test, $\mathrm{p}=0 \cdot 52$ ).

Comparison was also made with eye changes in the older subjects in the Jamaican Cohort Study who have angiographic assessments at annual intervals. Of the 43 SS subjects aged over 17 years at their 1992 assessment, the mean age was $17 \cdot 8$ (range $17 \cdot 0-18 \cdot 6$ ) years.

\section{HAEMATOLOGICAL METHODS}

The diagnosis of SS disease and of sickle cell $\beta^{0}$ thalassaemia was based on standard criteria. ${ }^{4}$ Routine haematological indices were measured in a Coulter STKR (Coulter Electronics) and $\mathrm{HbA} 2, \mathrm{HbF}$, the number of $\alpha$ globin genes, and the $\beta$ globin haplotype determined as previously reported. ${ }^{1}$

\section{OPHTHALMIC METHODS}

After assessment of best corrected visual acuity and pupillary dilatation, the fundus was examined by indirect ophthalmoscopy recording the number and position of haemorrhages, chorioretinal scars, retinal schisis cavities (collectively termed patches), and PSR lesions. Fluoroscopy and fluorescein angiography were performed after the injection of a bolus of $5 \mathrm{ml}$ of $20 \%$ sodium fluorescein. The extent of peripheral vascular border seen by indirect ophthalmoscopy was recorded and the border was defined as posterior if it was behind the equator.
The retinal vascular border as recorded by fluorescein angiography was graded according to a recent classification ${ }^{5}$ which appears to have prognostic significance. A type I border was qualitatively similar to normal with a smooth border formed of arteriovenous loops, the capillaries becoming longer and less densely packed as the border is approached. The border may differ from normal by being more posteriorly placed, and vascular anomalies internal to the border are more common than normal. A type II border is irregular, demonstrates a sharp demarcation between perfused and non-perfused retina with abrupt terminations of small or medium calibre vessels, and a dense capillary bed up to the margin of perfusion. This pattern was further subdivided into those manifesting capillary buds or stumps extending into nonperfused retina (type IIa) and those without (type IIb). In some angiograms, the border was unclassifiable either because it was too peripheral to photograph or the photographs were of poor quality. Examinations were performed by the two ophthalmologists $(\mathrm{SH}$, $\mathrm{AB})$ without knowledge of the geographical origin of the patients.

\section{STATISTICAL METHODS}

The $\chi^{2}$ test for association was used for nominal variables when the numbers were large enough. When the variables were ordered, the association was further investigated using the $\chi^{2}$ test for trend. When expected frequencies were too small, the variables were regrouped to a 2 by 2 table, and the association tested using Fisher's exact test. Logistic regression was used when it was necessary to take other factors into account. Comparison of two means was made using the $t$ test, with separate variance estimates when variances were not homogeneous. When there were more than two means, analysis of variance was used, with Bonferroni adjusted $\mathrm{p}$ values to test pairwise contrasts. The distribution of $\mathrm{HbF}$ was highly skewed and was transformed by $\log _{e}(\mathrm{HbF}+1)$ before analysis.

\section{Results}

Retinal vascular changes were identified in this study which were similar qualitatively to those seen in the Jamaican cohort comprising fresh vascular obstruction (Fig 1), posterior displacement of the vascular border, and abnormalities of the peripheral vasculature (Figs 2 and 3 ).

\section{COMPARISON OF SS DISEASE AND SICKLE CELI}

\section{$\mathrm{B}^{0}$ THALASSAEMIA}

There were only 10 patients with sickle cell $\beta^{0}$ thalassaemia so data from eastern, south western, and central regions were pooled for comparison with SS disease. The number of $\alpha$ globin genes (known in $53 \mathrm{SS}$, six $\mathrm{S} \beta^{0}$ thalassaemia) did not differ significantly between genotypes, there being $25 \alpha \alpha / \alpha \alpha$, $20 \alpha-/ \alpha \alpha$, and eight $\alpha-/ \alpha-$ in SS disease 


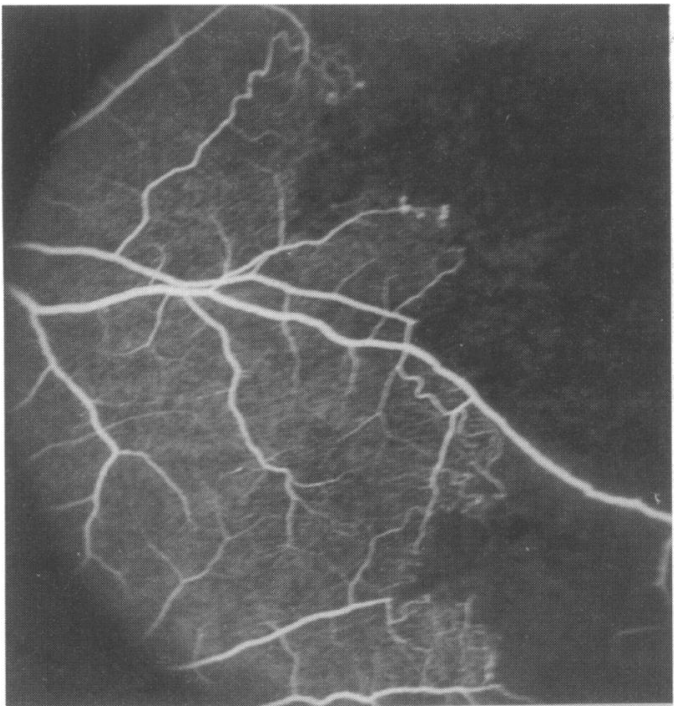

Figure 2 Fluorescein angiogram of a 29-year-old woman with $S S$ disease from the eastern region showing a type IIb border.

compared with two, three, one for $S \beta^{0}$ thalassaemia. There were no differences in presence of patches, degree of circumferential closure, or posterior closure between different genotypes. Patches occurred in $26 \mathrm{SS}$ and three $S \beta^{0}$ thalassaemia (Fisher's exact test, $p=0.70$ ), $>180^{\circ}$ of the vascular border was seen in $33 \mathrm{SS}$ and two $S \beta^{0}$ thalassaemia (Fisher's exact test, $p=0.093$ ), and posterior position occurred in $18 \mathrm{SS}$ and two $S \beta^{0}$ thalassaemia (Fisher's exact test, $p=0.84$ ). The angiographic description of retinal vascular border using a summary score of the worst affected eye did not differ between genotypes, type II borders occurring in 15/58 SS and in $0 / 10 S \beta^{0}$ thalassaemia (Fisher's exact test, $p=0 \cdot 13$ ). In summary, although the small sample of subjects with sickle cell $\beta^{0}$ thalassaemia renders the tests relatively insensitive, there did not appear to be major differences from SS disease.

REGIONAL DIFFERENCES IN HAEMATOLOGY OF SS DISEASE

The number of $\alpha$ globin genes was known in 33 eastern and 19 south western subjects, there being eight homozygotes for $\alpha$ thalassaemia $(\alpha-/ \alpha-), 13$ heterozygotes $(\alpha-/ \alpha \alpha)$, and 12 with a normal $\alpha$ globin gene complement $(\alpha \alpha / \alpha \alpha)$ in the east compared with 0 , six, and 14 in the south west. The trend of an increasing east:west ratio with decreasing number of $\alpha$ globin genes was statistically significant $(p<0.01)$. Total haemoglobin levels in eastern patients (mean 10.5, SD 1.5) were significantly higher than in the south west $(9 \cdot 4,1 \cdot 5)$ ( $t$ test, $\mathrm{p}=0.013)$. Fetal haemoglobin levels in eastern patients (median $12 \cdot 0 \%$, range $3 \cdot 3-22 \cdot 1$ ) were also significantly higher than in the south west (median $4.44 \%$, range $0.5-17.9$ ) ( $t$ test on transformed data, $\log _{\mathrm{e}}(\mathrm{HbF}+1)$, with separate variance estimates, $\mathrm{p}<0.001)$. Mean cell volume in the eastern patients (mean $83.0 \mathrm{fl}$, SD 11.1) was significantly lower than in south western patients (mean $89 \cdot 7 \mathrm{fl}, \mathrm{SD} 10 \cdot 4$ ) ( $t$ test, $\mathrm{p}=0.03$ ).

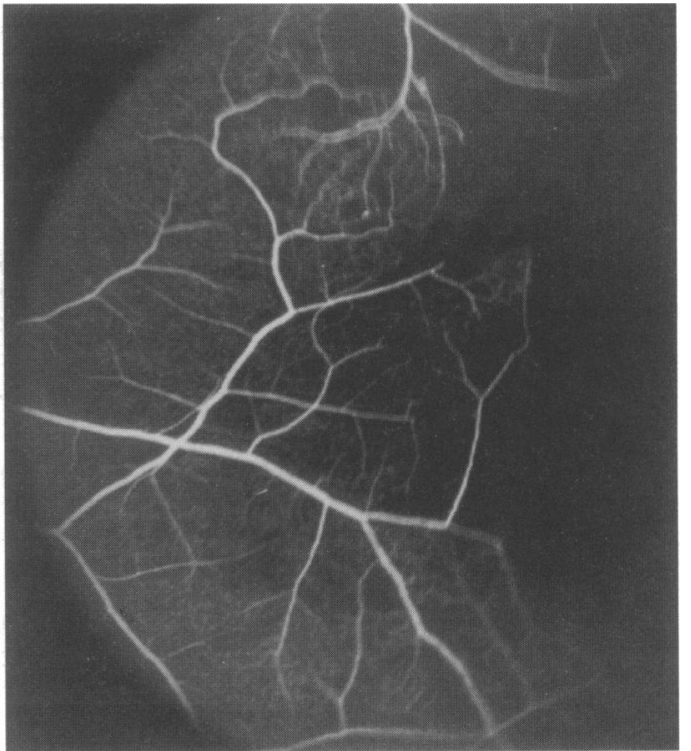

Figure 3 Fluorescein angiogram of a 23-year-old man with SS disease from the western region showing a type IIa border.

REGIONAL DIFFERENCES IN OPHTHALMOLOGY OF SS DISEASE

Visual acuity was $<6 / 12$ in seven $(18 \%)$ eastern patients and in three (15\%) of south western patients $(p=1.00$ using Fisher's exact test). Acuity was $<6 / 60$ in three $(4 \%)$ eyes of eastern subjects and in two (5\%) eyes of south western subjects none of which was attributable to sickle cell disease. Patches occurred in the peripheral retina of $16(40 \%)$ eastern patients and in $10(50 \%)$ of south western patients, this difference not reaching significance $\left(\chi^{2}\right.$ test, $\left.\mathrm{p}=0 \cdot 65\right)$.

In all patients the peripheral border of retinal vascularisation was seen, the circumferential extent being $>180^{\circ}$ in $20(50 \%)$ eastern patients and in $12(60 \%)$ south western subjects ( $\chi^{2}$ test, $\left.\mathrm{p}=0 \cdot 65\right)$. Total circumferential closure occurred bilaterally in 19 (48\%), unilaterally in one eastern patient, and bilaterally in $12(60 \%)$ south western patients. Posterior closure occurred in $11(28 \%)$ eastern and in six (30\%) south western patients, there being no regional difference $\left(\chi^{2}\right.$ test, $\left.\mathrm{p}=1 \cdot 00\right)$.

Classification of the retinal border on fluorescein angiography was possible in 71 $(89 \%)$ eyes of eastern and in $38(95 \%)$ eyes of south western patients (Table 1). Border type IIa was significantly more frequent in south western patients (Fisher's exact test, $p=0.03$ ). Proliferative sickle retinopathy occurred in one subject, a 35-year-old man from the south west.

\section{EYE VARIABLES AND HAEMATOLOGY}

The regional differences in haematology imply that analysis of the relation between eye variables and haematology should take region into account using analysis of variance. Subjects with $>180^{\circ}$ of the anterior border seen had a lower $\mathrm{HbF}$ compared with those with $\leqslant 180^{\circ}$ (Table 2). The relation between the extent of the border seen and $\alpha$ thalassaemia (heterozygous and homozygous forms combined) appeared to differ in the two 
Table 1 Angiographic classification of the peripheral retinal vascular border in SS patients from the two regions of Saudi Arabia. Each eye is scored as to the most serious characteristic, and the summary score refers to a subject scored as to the eye with the most serious characteristic

\begin{tabular}{llllllll}
\hline & \multicolumn{3}{l}{ Eastern region (\%) } & & & \multicolumn{2}{l}{ Western region (\%) } \\
\cline { 2 - 3 } \cline { 8 - 9 } $\begin{array}{l}\text { Border } \\
\text { type }\end{array}$ & $\begin{array}{l}\text { Left } \\
\text { eye }\end{array}$ & $\begin{array}{l}\text { Right } \\
\text { eye }\end{array}$ & $\begin{array}{l}\text { Summary } \\
\text { score }\end{array}$ & & $\begin{array}{l}\text { Left } \\
\text { eye }\end{array}$ & $\begin{array}{l}\text { Right } \\
\text { eye }\end{array}$ & $\begin{array}{l}\text { Summary } \\
\text { score }\end{array}$ \\
\hline I & $33(87)$ & $28(85)$ & $31(82)$ & & $13(68)$ & $12(63)$ & $12(63)$ \\
IIa & $1(3)$ & 0 & $1(3)$ & & $5(26)$ & $4(21)$ & $5(26)$ \\
IIb & $4(11)$ & $5(15)$ & $6(16)$ & & $1(5)$ & $3(16)$ & $2(11)$ \\
Total & 38 & 33 & 38 & & 19 & 19 & 19 \\
\hline
\end{tabular}

regions. There was no association in the eastern province, $\alpha$ thalassaemia occurring in $10 / 15$ subjects with $\leqslant 180^{\circ}$ compared with $11 / 18$ subjects with $>180^{\circ} \quad(p=1.00$ using Fisher's exact test). In south western patients, $\alpha$ thalassaemia occurred in $0 / 7$ with $\leqslant 180^{\circ}$ and in $6 / 12$ with $>180^{\circ}$ (Fisher's exact test, $\mathrm{p}=0.04$ ), suggesting $\alpha$ thalassaemia as a risk factor for posterior displacement of the vascular border.

Patches were associated with lower $\mathrm{HbF}$ and lower mean cell volume. There were no associations between age, haematology, and number of $\alpha$ globin genes with either posterior closure or border scores (Table 2).

\section{COMPARISON WITH JAMAICAN DATA}

When compared with subjects in the two regions of Saudi Arabia, Jamaican patients had significantly lower $\mathrm{HbF}$ (mean $7 \cdot 9$, SD $1 \cdot 2$ ) than either region, lower $\mathrm{HbF}$ (median $4 \cdot 5$, range $0 \cdot 4-14 \cdot 9$ ) than eastern subjects only, similar mean cell volume values (mean 84.8 , SD 8.9 ) to those of both regions and significantly less $\alpha$ thalassaemia ( $30 \alpha \alpha / \alpha \alpha$, $13 \alpha-/ \alpha \alpha, 0 \alpha-/ \alpha-)$ than the eastern region.

The presence of patches (26 (43\%) Saudi patients, $24(59 \%)$ Jamaicans) and of posterior closure $(17(28 \%)$. Saudi patients, 14 (33\%) Jamaican patients) did not differ between the groups ( $\chi^{2}$ test, $p=0.19$ and $p=0.75$ respectively). The proportion of patients with $>180^{\circ}$ of the circumference of the vascular border seen (32/60 Saudi patients, 39/42 Jamaican patients) was significantly greater in Jamaicans $\left(\mathrm{p}<0.001\right.$ using $\chi^{2}$ test). Comparison of angiographic border type showed that type IIa was significantly more common in south western patients $(5 / 19)$ than in Jamaicans (1/36) (Fisher's exact test, $p=0.03$ ), there being no difference between eastern Saudi patients and Jamaicans (Fisher's exact test, $\mathrm{p}=1 \cdot 00$ ).

\section{Discussion}

Despite the small number of patients in this study it is clear that SS disease in Saudi Arabia is associated with peripheral retinal vessel changes which are similar to those seen in the subjects of African origin. The finding that 10 $(14 \%)$ of patients had sickle cell $\beta^{0}$ thalassaemia among 71 subjects with an SS phenotype, suggests a greater relative frequency of this genotype than occurs in populations of African origin. The retinal involvement in sickle cell $\beta^{0}$ thalassaemia was similar to that in SS disease although no patients with $S \beta^{0}$ thalassaemia had a type II border in this study.

It was of interest to assess whether retinal vascular involvement differed between the two regions since the Benin haplotype occurs in the south west and the Asian haplotype accounts almost exclusively for the disease in the eastern province, and eastern patients showed a greater frequency of $\alpha$ thalassaemia, higher total haemoglobin and $\mathrm{HbF}$ levels, and lower values of mean cell volume. The type IIa border, which indicates a threat of proliferative retinopathy, was more common in south western patients among whom was the only case of proliferative disease. However, the presence of patches in the peripheral retina, or peripheral retinal vessel change as determined by either circumferential or posterior extent was not different.

The haematological correlates of these retinal changes were less clear. A low $\mathrm{HbF}$ level was significantly associated with more retinal patches and with a greater extent of circumferential retinal closure, those observations being consistent with the documented inhibitory effect of high $\mathrm{HbF}$ levels on polymerisation of $\mathrm{HbS}$ molecules, sickling, and presumed vaso-occlusion. However, the higher $\mathrm{HbF}$ in eastern patients was not reflected in a lower prevalence of patches and less retinal closure as might have been expected. $\alpha$ Thalassaemia also inhibits sickling probably through its effect in lowering the haemoglobin concentration within cells, and in Jamaican studies $\alpha$ thalassaemia reduced the risk of retinal closure. ${ }^{67}$ The greater frequency of an unstable retinal border in south western patients was not clearly attributable to the lower frequency of $\alpha$ thalassaemia or the lower $\mathrm{HbF}$ levels in these patients, but because of the small numbers, these analyses were relatively insensitive. It was of interest that the high frequency of $\alpha$ thalassaemia in the eastern province did not appear to protect against vascular changes.

Table 2 Relation between ocular findings $\geqslant 180$ of the vascular border seen, presence of patches, posterior position of the vascular border, and border classified as II) and age and haematological indices

\begin{tabular}{|c|c|c|c|c|c|}
\hline & \multicolumn{4}{|c|}{ Adjusted mean differences ( $95 \%$ confidence interval) } & \multirow{2}{*}{$\begin{array}{l}\text { Adjusted odds ratio } \\
\text { ( } 95 \% \text { CI) for } \\
\alpha \text { thalassaemia }\end{array}$} \\
\hline & Age & $H b$ & $\log _{\mathrm{e}}(H b F+1)^{\star}$ & $M C V$ & \\
\hline Vascular border seen & $-0.9(-4 \cdot 3,-2 \cdot 4)$ & $-0.1(-0.9,0.7)$ & \multirow{4}{*}{$\begin{array}{l}\mathrm{W}-0.3(-1 \cdot 0,0 \cdot 4) \\
\mathrm{E}-0 \cdot 3(-0.5,0 \cdot 0) \\
\mathrm{W}-0 \cdot 6(-1,2,0 \cdot 1) \\
\mathrm{E}-0 \cdot 3(-0.5,0.0) \\
\mathrm{W} 0 \cdot 3(-0.4,1 \cdot 0) \\
\mathrm{E}-0 \cdot 1(-0.4,0 \cdot 2) \\
\mathrm{W} 0 \cdot 0(-0.7,0 \cdot 7) \\
\mathrm{E}-0 \cdot 1(-0.5,0 \cdot 2)\end{array}$} & $-3 \cdot 2(-8 \cdot 8,2 \cdot 5)$ & See text \\
\hline Patches & $-2 \cdot 2(-5 \cdot 5,1 \cdot 2)$ & $-0 \cdot 2(-1 \cdot 0,0 \cdot 6)$ & & $-7 \cdot 5(-12 \cdot 9-2 \cdot 1)$ & $2 \cdot 6(0 \cdot 7,9 \cdot 1)$ \\
\hline Posterior border & $-0 \cdot 4(-4 \cdot 1,3 \cdot 4)$ & $0 \cdot 7(-0 \cdot 2,1 \cdot 5)$ & & $-2 \cdot 1(-8 \cdot 4,4 \cdot 3)$ & $1 \cdot 0(0 \cdot 3,3 \cdot 8)$ \\
\hline Border classification & $0 \cdot 0(-0 \cdot 4,3 \cdot 9)$ & $0 \cdot 7(-0 \cdot 3,1 \cdot 6)$ & & $2 \cdot 5(-4 \cdot 4,9 \cdot 4)$ & $1 \cdot 2(0 \cdot 3,5 \cdot 1)$ \\
\hline
\end{tabular}

*Variance differed between regions so regions presented separately. $\mathrm{MCV}=$ mean cell volume. 
Comparison with the Jamaican cohort study should be treated with caution because of the difference in mean ages $(27.7$ years for Saudi patients, $17 \cdot 8$ years for Jamaicans), and the Saudi patients were not derived from unselected population base. In Jamaican subjects the extent of vascular border seen was greater, despite their younger mean age, suggesting a factor inhibiting vessel closure in both regions of Saudi Arabia in early life. ${ }^{5}$ This factor is unlikely to be the frequency of high $\mathrm{HbF}$ levels or $\alpha$ thalassaemia since these did not differ between south western Saudi and Jamaican patients. Furthermore, the type IIa border was more common in south western than Jamaican patients, possibly reflecting the greater mean age of south western Saudi patients, a specific risk factor, or the symptomatic bias inherent in patients attending a tertiary referral hospital. The greater prevalence of an unstable type IIa border may be relevant for visual prognosis since this border implies threat of PSR which may in turn lead to visual loss. By contrast, a type I border, however posteriorly placed, is not followed by this complication and may be protective of proliferative disease. ${ }^{5}$

Overall, despite minor differences, the ocular pathology in SS patients from each region of Saudi Arabia and differed little from that observed in Jamaicans with SS disease. That this is the case despite differences in haematological variables and clinical features should not be surprising, since visually threatening retinal vascular disease is seen most commonly in forms of sickle cell disease which may otherwise be relatively mild. Although no case in this study had lost vision as a consequence of their haemoglobinopathy, the number of cases was small, and it is likely that SS disease represents a threat to vision in Saudi Arabia albeit small. The more florid retinal pathology often observed in Jamaican patients is generally attributable to sickle cell haemoglobin C (SC) disease or sickle cell $\beta^{+}$ thalassaemia which were not encountered in Saudi Arabia. ${ }^{5}$

We thank Dr Gudrun Brismar, head of the division of ophthalmology, Department of Surgery for permission to use the facilities of that department, and Dr Muir Jackson and his staff in the haematology section, Department of Pathology and Abdulkareem, Mr Mohammed Dokmak, Mr Ahmed Aba Wazeid, and Mrs Fawzia El Elimy provided administrative assistance.

1 Padmos MA, Roberts GT, Sackey K, Kulozik A, Bail S, Morris JS, et al. Two different forms of homozygous sickle cell disease occur in Saudi Arabia. Br $\mathcal{F}$ Haematol 1991; 79: 93-8.

2 Kulozik AE, Wainscoat JS, Serjeant GR, Kar BC, Al-Awamy $\mathrm{B}$, Essan GJF, et al. Geographical survey of $\beta$-globin gene haplotypes: evidence for an independent Asian origin of the

3 Pembrey ME, Wood WG, Weatherall DJ, Perrine RP. Fetal haemoglobin production and the sickle gene in the Oases haemoglobin production and the sickle gene in the Oases 4 Serjeant GR. Sickle cell disease. 2nd ed. Oxford: Oxford University Press, 1992

5 Penman AD, Talbot JF, Chuang EL, Thomas P, Serjeant GR, Bird AC. A new classification of peripheral retinal vascular changes in sickle cell disease: relevance to sight threatening disease. $\mathrm{Br} \mathcal{F}$ Ophthalmol 1994; 78: 681-90.

6 Talbot JF, Bird AC, Rabb LM, Maude GH, Serjeant GR. Sickle cell retinopathy in Jamaican children - a search for Sickle cell retinopathy in Jamaican children - a search
prognostic factors. $B r f$ Ophthalmol $1983 ; 67: 782-5$.

7 Talbot JF, Bird AC, Maude GH, Acheson RW, Moriarty BJ, Serjeant GR. Sickle cell retinopathy in Jamaican children: further observations from a cohort study. $\mathrm{Br} \mathcal{F}$ Ophthalmol 1988; 72: 727-32. 